\title{
Belajar Subtema 3 Lingkungan dan Manfaatnya dengan Media Pembelajaran Interaktif Berbasis Articulate Storyline 3
}

\author{
Ni Ayu Ketut Sinta ${ }^{1 *}$, I Gede Astawan², I Made Suarjana ${ }^{3}$
}

1,2,3 Jurusan Pendidikan Dasar, Universitas Pendidikan Ganesha, Singaraja, Indonesia

\section{ART ICLE IN F O}

Article history:

Received May 09, 2021

Revised May 15, 2021

Accepted June 30, 2021

Available online July 25, 2021

Kata Kunci:

Lingkungan, Media

Interaktif, Articulate

Storyline

Keywords:

Environment, Interactive Media, Articulate Storyline

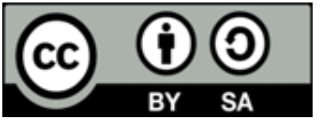

This is an open access article under the CC BY-SA license.

Copyright $(2021$ by Author. Published by Universitas Pendidikan Ganesh

\begin{abstract}
A B S T R A K
Kegiatan belajar subtema 3 lingkungan dan manfaatnya dari rumah kurang efektif akibat kurangnya ketersediaan media pembelajaran, sehingga proses pembelajaran tidak berjalan dengan optimal. Penelitian ini bertujuan untuk menghasilkan prototype media, menghasilkan media pembelajaran interaktif berbasis Articulate Storyline 3 dengan games yang teruji validitasnya serta respon praktisi dan peserta didik terhadap media. Penelitian pengembangan ini dilaksanakan dengan menggunakan model ADDIE. Subjek pada penelitian ini terdiri dari 2 ahli materi, 2 ahli media, 2 ahli desain, 1 praktisi, 3 peserta didik untuk respon perorangan, dan 6 peserta didik untuk respon kelompok kecil, sedangkan objek penelitian ini adalah validitas media. Metode pengumpulan data menggunakan metode rating scale, kuesioner, wawancara, observasi dan studi dokumen, untuk mengukur validitas media ini, digunakan instrumen rating scale berskala 4 dengan analisis data menggunakan rumus validitas Aiken dan respon praktisi dan peserta didik menggunakan rumus mean. Pengembangan media pembelajaran interaktif berbasis Articulate Storyline 3 dengan games dinyatakan valid dengan indeks validitas ahli materi, ahli media, ahli desain memperoleh hasil terendah 0,67 dan tertinggi 1. Hasil respon praktisi, respon perorangan dan kelompok kecil memperoleh kategori sangat baik. Jadi, media pembelajaran interaktif berbasis Articulate Storyline 3 dengan games pada subtema 3 lingkungan dan manfaatnya khususnya pada muatan IPA layak untuk digunakan dalam pembelajaran.
\end{abstract}

\section{A B S T R A C T}

Learning activities for sub-theme 3 of the environment and its benefits from home are less effective due to the lack of availability of learning media, so that the learning process does not run optimally. This study aims to produce media prototypes, produce interactive learning media based on Articulate Storyline 3 with games whose validity has been tested and the responses of practitioners and students to the media. This development research was carried out using the ADDIE model. The subjects in this study consisted of 2 material experts, 2 media experts, 2 design experts, 1 practitioner, 3 students for individual responses, and 6 students for small group responses, while the object of this study was media validity. The data collection method uses a rating scale method, questionnaires, interviews, observations and document studies, to measure the validity of this media, a rating scale instrument is used on a scale of 4 with data analysis using the Aiken validity formula and the responses of practitioners and students using the mean formula. The development of interactive learning media based on Articulate Storyline 3 with games was declared valid with the validity index of material experts, media experts, design experts getting the lowest results of 0.67 and the highest 1. The results of practitioners' responses, individual and small group responses received very good categories. So, interactive learning media based on Articulate Storyline 3 with games on subtheme 3 of the environment and its benefits, especially on science content, are suitable for use in learning.

\section{PENDAHULUAN}

Saat ini, seluruh dunia tidak terkecuali di Indonesia dilanda pandemi covid-19, hal ini sangat berdampak pada semua sektor tidak terkecuali dengan sektor pendidikan (Dewi, 2020; Syah, 2020). Pendidikan di Indonesia yang seharusnya pembelajaran tatap muka terpaksa diliburkan terlebih dahulu dan diganti dengan pembelajaran jarak jauh (belajar dari rumah) melalui pembelajaran daring (Dong et al., 2020; Mishra et al., 2020; Sukendro et al., 2020). Dengan berlangsungnya pembelajaran daring guru diharuskan dapat memanfaatkan teknologi informasi dan komunikasi dalam proses pembelajaran jarak jauh. Salah satu pembelajaran daring yang dilakukan yaitu pembelajaran IPA. Ilmu Pengetahuan Alam (IPA) merupakan ilmu yang mempelajari peristiwa- 
peristiwa yang terjadi di alam yang terkontruksi baik secara personal maupun sosial (Putri et al., 2018). Sejalan dengan pendapat tersebut, IPA adalah suatu kegiatan yang dilakukan dengan sistematis untuk mengumpulkan informasi-informasi tentang alam (Saptiani \& Astawan, 2020). Agar pembelajaran daring berjalan dengan optimal dan dapat mencapai tujuan pembelajaran dapat dilakukan dengan menggunakan media pembelajaran. Penggunaan media pembelajaran dalam proses pembelajaran diperlukan untuk mempermudah penyampaian materi pembelajaran yang dilakukan oleh guru. Selain itu, penggunaan media dalam kegiatan pembelajaran diharapkan mampu membentuk stimulus agar tercapainya tujuan pembelajaran (Luh et al., 2021; Wahyuningtyas \& Suteng, 2020). Media pembelajaran dibuat berdasarkan karakteristik peserta didik. Peserta didik sekolah dasar memiliki karakteristik lebih senang apabila pembelajaran dilakukan sambil bermain. Media dengan memanfaatkan teknologi dan adanya konsep permainan dapat meningkatkan motivasi peserta didik untuk belajar (Abdulrahaman et al., 2020; Andreani \& Ying, 2019). Media pembelajaran yang baik harus memenuhi tiga syarat yaitu deduktif, teknik pembuatan dan keindahan (Asyhari \& Silvia, 2016). Pada pembelajaran IPA seharusnya guru dapat menciptakan pembelajaran yang inovatif, kreatif, aktif, dan menyenangkan, terlebih lagi pada pembelajaran daring yang memerlukan media pembelajaran berbasis teknologi. Dengan demikian penggunaan media dalam pembelajaran sangat diperlukan.

Namun kenyataannya berdasarkan hasil observasi dan wawancara di SD Negeri 1 Pertima, didapatkan bahwa pemanfaatan teknologi sebagai penunjang dalam kegiatan belajar mengajar pada muatan IPA belum optimal, kurangnya media pembelajaran daring yang efektif, keterbatasan materi pada muatan IPA yang tersaji dalam buku teks, dan hasil belajar IPA peserta didik masih rendah hal ini disebabkan karena kurangnya kemauan peserta didik belajar. Peserta didik merasa bosan dengan pembelajaran yang monoton yang hanya menggunakan metode ceramah tanpa adanya media-media yang menarik perhatian peserta didik. Permasalahan serupa juga ditemukan pada penelitian sebelumnya yaitu peserta didik bosan dengan pembelajaran yang monotun (Courage, 2016). Inovasi sangat perlu dilakukan dalam proses pembelajaran untuk dapat mengatasi kejenuhan peserta didik dan dapat meningkatkan kemampuan berpikir peserta didik (Ruipérez-Valiente \& Kim, 2020; Tuma et al., 2021). Penyajian materi yang kreatif dan menarik akan memberikan pengaruh positif dan meningkatnya kemauan peserta didik untuk belajar (Huang et al., 2020; Mahesti \& Koeswanti, 2021). Jadi, Apabila tidak dilakukan perbaikan terkait masalah yang dialami seperti kurangnya media pembelajaran daring yang efektif maka akan berdampak pada kualitas proses pembelajaran dan menurunnya motivasi peserta didik untuk belajar.

Alternatif solusi yang dapat mengatasi permasalahn tersebut yaitu dengan mengembangkan media pembelajaran interaktif berbasis Articulate Storyline 3. Media pembelajaran interaktif berbasis Articulate Storyline efektif untuk di digunakan dalam pembelajaran dilihat dari validitas media dan respon peserta didik terhadap media yang memperoleh respon yang sangat positif (Entis Sutisna, Lina Novita, 2020). Multimedia interaktif pembelajaran mandiri berbasis Articulate Storyline 3 yang diberi nama "PERI GITA" layak digunakan dari segi media dan praktisi (Rianto, 2020). Media interaktif berbasis Articulate Storyline layak digunakan untuk membantu guru menyampaikan materi pembelajaran dari segi materi, media dan minat peserta didik. Dalam pengembangan media menggunakan aplikasi Articulate Storyline versi pertama (Sari \& Harjono, 2021). Pengaruh penggunaan media pembelajaran interaktif berbasis Articulate Storyline terhadap motivasi dan hasil belajar IPS peserta didik (Setyaningsih et al., 2020). Multimedia interaktif berbasis Articulate Storyline 3 untuk meningkatkan minat belajar peserta didik pada pembelajaran tematik terpadu di kelas III SD praktis digunakan dalam proses pembelajaran berdasarkan hasil uji validitas materi, uji validitas bahasa, uji validitas, uji praktikalitas dan respon guru (Aulia \& Masniladevi, 2021). Media pembelajaran tema 3 subtema 3 berbasis Articulate Storyline 3 dinyatakan valid terdiri dari materi pembelajaran dan kuis (Salwani \& Ariani, 2021). Berdasarkan beberapa penelitian terdahulu maka media pembelajaran interaktif berbasis Articulate Storyline 3 dinyatakan layak. Keterbaharuan yang dilakukan yaitu dengan menambahkan games pembelajaran pada media yang akan dikembangkan. Dengan demikian, maka dikembangkannya media pembelajaran interaktif berbasis Articulate Storyline 3 dengan games pada subtema 3 lingkungan dan manfaatnya kelas V SD. Tujuan penelitian ini adalah untuk menciptakan pengembangan media pembelajaran berbasis Articulate Storyline 3 dengan games pada subtema 3 lingkungan dan manfaatnya kelas V SD dan untuk mengembangkan media pembelajaran berbasis Articulate Storyline 3 dengan games pada subtema 3 lingkungan dan manfaatnya kelas V SD yang teruji validitasnya serta mendaptakn respon praktisi dan peserta didik terhadap media ini. Berdasarkan hal tersebut, maka dilakukan pengembangan media pembelajaran berbasis Articulate Storyline 3 dengan games pada subtema 3 lingkungan dan manfaatnya kelas V SD dan diharapkan media ini efektif serta dapat membantu guru dan siswa dalam kegiatan pembelajaran pada berbagai situasi pembelajaran tanpa terbatas waktu dan ruang.

\section{METODE}

Dalam penelitian ini dikembangkan media pembelajaran interaktif berbasis Articulate Storyline 3 dengan games pada subtema 3 lingkungan dan manfaatnya kelas V SD menggunakan model pengembangan ADDIE (Analyze, Design, Development, Implementation, and Evaluations). Model ADDIE merupakan model yang 
dikembangkan oleh Dick and Carry (dalam Harjanta \& Herlambang, 2018; Wijayanto \& Santoso, 2017). Namun karena adanya beberapa kendala seperti pandemic Covid-19, keterbatasan waktu, dan finansial maka pengembangan media pembelajaran interaktif berbasis Articulate Storyline 3 dengan games pada subtema 3 lingkungan dan manfaatnya kelas V SD hanya dapat dilaksanakan melalui tiga tahapan yaitu analisis, desain, dan pengembangan.

Tahap analyze (analisis) dilakukan analisis kurikulum dengan menganalisis KI, KD, indikator pencapaian kompetensi. Selanjutnya, dibandingkan dengan materi yang termuat pada buku peserta didik dan LKS. Analisis kebutuhan dilakukan dengan melakukan observasi dan wawancara kepada guru kelas V di SD Negeri 1 Pertima untuk mengetahui secara pasti apa yang dibutuhkan di lapangan atau di sekolah. Analisis karakteristik peserta didik dilakukan untuk mengetahui kecocokan dan kesiapan peserta didik kelas V SD dalam menggunakan media pembelajaran interaktif berbasis Articulate Storyline 3 dengan games. media dilakukan dengan mengumpulkan informasi-informasi terkait perencanaan media yang baik sehingga dapat dijadikan referensi dalam pengembangan media pembelajaran interaktif berbasis Articulate Storyline 3 dengan games. Tahap design (desain) dilakukan dengan penyusunan prototype (rancang bangun) media pembelajaran interaktif dan menetapkan desain tampilan (background) dari media pembelajaran interaktif. Tahap development (pengembangan) dilakukan pembuatan produk secara nyata berdasarkan analisis dan desain yang telah dipikirkan dan dikonsultasikan dengan dosen pembimbing. Setelah melakukan pengembangan media pembelajaran interaktif berbasis Articulate Storyline 3 dengan games pada subtema 3 lingkungan dan manfaatnya kelas V SD, kemudian dilakukan uji coba media ini dengan review dua ahli materi, dua ahli media, dan dua ahli desain. Selanjutnya mencari respon satu praktisi dan peserta didik melaui uji perorangan 3 orang dan uji kelompok kecil dengan 6 orang kemudian dianalisis melakukan revisi produk dan kemudian akan menghasilkan produk akhir.

Subjek penelitian ini yaitu media pembelajaran interaktif berbasis Articulate Storyline 3 dengan games diuji oleh ahli materi, ahli media dan ahli desain yang berkompeten dibidang media dan teknologi serta respon praktisi dan peserta didik. Objek uji coba penelitian ini adalah validitas media pembelajaran interaktif berbasis Articulate Storyline 3 pada subtema 3 lingkungan dan manfaatnya kelas V SD. Jenis data pada penelitian ini ada dua, yaitu dikelompokan menjadi dua yaitu data kualitatif dan data kuantitatif. Data kualitatif merupakan data yang berbentuk kata, skema maupun gambar, sementara data kuantitatif adalah data yang berupa angka dan analisis menggunakan statistik (Sugiyono, 2015). Instrumen pengumpulan data yang digunakan dalam penelitian ini yaitu rating scale dengan menggunakan instrumen skala 1-4. Dalam penelitian ini validitas instrumen dapat dipastikan dengan membuat kisi-kisi instrumen. Kisi-kisi instumen respon praktisi merupakan gabungan dari ahli materi, media dan desain. Berikut kisi-kisi instumen ahli materi, ahli media, ahli desain, respon perorangan dan kelompok kecil disajikan pada Tabel 1, Tabel 2, Tabel 3, dan Tabel 4.

Tabel 1. Kisi-kisi Instrumen Ahli Materi

\begin{tabular}{|c|c|c|c|c|c|}
\hline No & Aspek & & Indikator & $\begin{array}{l}\text { Nomor } \\
\text { Butir }\end{array}$ & Jumlah Butir \\
\hline 1 & Kurikulum & 1) & $\begin{array}{l}\text { Kesesuaian materi dengan kompetensi dasar, } \\
\text { indikator, dan tujuan pembelajaran }\end{array}$ & $1,2,3$ & 3 \\
\hline \multirow[t]{2}{*}{2} & Materi & 2) & $\begin{array}{l}\text { Kebenaran, keruntutan, kelengkapan, dan } \\
\text { kedalaman konsep materi yangdisajikan }\end{array}$ & $4,5,6,7$ & \\
\hline & & 3) & $\begin{array}{l}\text { Kesesuaian materi dengan karakteristik peserta } \\
\text { didik dan materi didukung dengan media yang } \\
\text { tepat }\end{array}$ & $8,9,10$ & 7 \\
\hline 3 & Tata Bahasa & 4) & $\begin{array}{l}\text { Penggunaan bahasa dan bahasa yang digunakan } \\
\text { sesuai dengan karakteristik peserta didik }\end{array}$ & 11,12 & 2 \\
\hline
\end{tabular}

Tabel 2. Kisi-kisi Instrumen Ahli Media

\begin{tabular}{|c|c|c|c|c|c|}
\hline No & Aspek & & Indikator & Nomor Butir & $\begin{array}{l}\text { Jumlah } \\
\text { Butir }\end{array}$ \\
\hline \multirow[t]{3}{*}{1} & Desain tampilan & 1) & Kesesuaian desain tampilan & $1,2,3,4$ & \\
\hline & & 2) & Kesesuain tata letak menu dan tombol & $5,6,7,8$ & 11 \\
\hline & & 3) & Ukuran, warna, dan jenis font & $9,10,11$ & \\
\hline 2 & Video & 4) & Kesesuaian video dengan materi & 12 & 1 \\
\hline 3 & Animasi & 5) & Ketepatan animasi & 13,14 & 2 \\
\hline 4 & $\begin{array}{l}\text { Kemudahan } \\
\text { penggunaan media }\end{array}$ & 6) & Usefull & $15,16,17$ & 3 \\
\hline
\end{tabular}


Tabel 3. Kisi-kisi Instrumen Ahli Desain

\begin{tabular}{|c|c|c|c|c|c|}
\hline No & Aspek & & Indikator & Nomor Butir & $\begin{array}{l}\text { Jumlah } \\
\text { Butir }\end{array}$ \\
\hline \multirow[t]{4}{*}{1} & Ketepatan & 1) & $\begin{array}{l}\text { Tujuan pembelajaran sudah sesuai dengan } \\
\text { format } A B C D\end{array}$ & 1 & \multirow{4}{*}{3} \\
\hline & & 2) & $\begin{array}{l}\text { Kesesuaian media pembelajaran interaktif } \\
\text { dengan karakteristik peserta didik }\end{array}$ & 2 & \\
\hline & & 3) & Kesesuaian materi dengan tujuan & 3 & \\
\hline & & 4) & $\begin{array}{l}\text { Materi dalam media pembelajaran } \\
\text { interaktif dikemas secara runtut. }\end{array}$ & 4 & \\
\hline \multirow[t]{3}{*}{2} & Kejelasan & 5) & $\begin{array}{l}\text { Bahasa yang digunakan mudah dipahami } \\
\text { peserta didik }\end{array}$ & 5 & \multirow{3}{*}{3} \\
\hline & & 6) & Kejelasan uraian dan pembahasan & 6 & \\
\hline & & 7) & Kejelasan konten yang disediakan & 7 & \\
\hline \multirow[t]{2}{*}{3} & Minat/perhatian & 8) & $\begin{array}{l}\text { Media pembelajaran interaktif memotivasi } \\
\text { minat belajar }\end{array}$ & 8 & \multirow{2}{*}{2} \\
\hline & & 9) & $\begin{array}{l}\text { Meningkatkan perhatian peserta didik pada } \\
\text { pembelajaran }\end{array}$ & 9 & \\
\hline 4 & Kualitas kuis & 10) & $\begin{array}{l}\text { Konsistensi kuis dengan tujuan pembelajaran } \\
\text { dalam media pembelajaran interaktif }\end{array}$ & 10 & 1 \\
\hline 5 & $\begin{array}{l}\text { Dapat } \\
\text { memberikan } \\
\text { dampak bagi } \\
\text { peserta didik }\end{array}$ & 11) & $\begin{array}{l}\text { Memudahkan pemahaman peserta didik } \\
\text { terhadap materi }\end{array}$ & 11 & 1 \\
\hline
\end{tabular}

Tabel 4. Kisi-kisi Instrumen Respon Perorangan dan Kelompok Kecil

\begin{tabular}{|c|c|c|c|c|c|}
\hline No & Aspek & & Indikator & Nomor Butir & $\begin{array}{c}\text { Jumlah } \\
\text { Butir }\end{array}$ \\
\hline \multirow[t]{3}{*}{1} & $\begin{array}{l}\text { Menarik minat } \\
\text { peserta didik }\end{array}$ & 1) & tampilan media & 1 & \multirow{3}{*}{3} \\
\hline & & 2) & $\begin{array}{l}\text { Kemenarikan } \\
\text { ditampilkan }\end{array}$ gambar $\quad$ yang & 2 & \\
\hline & & 3) & $\begin{array}{l}\text { Kejelasan dan kemenarikan warna yang } \\
\text { disajikan }\end{array}$ & 3 & \\
\hline \multirow[t]{3}{*}{2} & Penyajian Materi & 4) & Materi yang disajikan jelas & 4 & \multirow{3}{*}{3} \\
\hline & & 5) & Materi yang disajikan mudah dipahami & 5 & \\
\hline & & 6) & $\begin{array}{l}\text { Contoh yang diberikan dalam materi mudah } \\
\text { dipahami }\end{array}$ & 6 & \\
\hline 3 & $\begin{array}{l}\text { Meningkatkan } \\
\text { perhatian peserta } \\
\text { didik }\end{array}$ & 7) & $\begin{array}{l}\text { Media pembelajaran interaktif mampu } \\
\text { meningkatkan perhatian peserta didik }\end{array}$ & 7 & 1 \\
\hline \multirow[t]{2}{*}{4} & Memotivasi & 8) & $\begin{array}{l}\text { Media pembelajaran interaktif mampu } \\
\text { memotivasi peserta didik }\end{array}$ & 8 & \multirow[t]{2}{*}{2} \\
\hline & & 9) & Huruf dapat dibaca dengan jelas & 9 & \\
\hline
\end{tabular}

Kemudian instrumen yang telah dibuat diuji judges untuk mengetahui validitas isi dan reliabilitas instrumen. Uji validitas isi pada penelitian ini menggunakan rumus Gregory. Data yang diperoleh dikonversikan ke dalam tabulasi silang $2 \times 2$ yang disajikan pada Tabel 5 .

Tabel 5. Perhitungan Validitas Isi Menurut Gregory

\begin{tabular}{cccc}
\hline \multirow{2}{*}{ Judges } & & \multicolumn{3}{c}{ Judges I } \\
\cline { 2 - 4 } & Penilaian Judges & Kurang Relevan & Sangat Relevan \\
\hline \multirow{2}{*}{ Judges II } & Kurang relevan & A (--) & B (-+) \\
& Sangat relevan & C (+-) & D (++) \\
\hline
\end{tabular}

Hasil uji validitas isi instrumen penilaian ahli materi, ahli media, ahli desain, praktisi, uji coba perorangan dan kelompok kecil secara berurutan yaitu 1,00, 0,94, 1,00, 0,98, dan 1,00 dengan kriteria validitas 
isi instrumen sangat baik sehingga layak digunakan untuk mengukur validitas dari media pembelajaran interaktif berbasis Articulate Storyline 3 dengan games. Dalam penelitian ini dilakukan uji reliabilitas dengan rumus percentage of agreements. Hasil uji reliabilitas instrument ahli materi, ahli media, ahli desain, praktisi, uji coba perorangan dan kelompok kecil secara berurutan yaitu 100\%, 94\%, 100\%, 98\%, dan 100\% dengan kriteria derajat reliabilitas sangat tinggi. Teknik analisis data yang digunakan yaitu teknik analisis deskriptif kuantitatif dan kualitatif. Analisis deskriptif kualitatif dilakukan dengan cara mengolah data berupa saran dan komentar para ahli untuk memperbaiki media pembelajaran interaktif berbasis Articulate Storyline 3 dengan games. Analisis deskriptif kuantitatif dilakukan dengan rumus valititas Aiken untuk para ahli dan rumus mean untuk respon praktisi dan peserta didik melalui perorangan dan kelompok kecil.

\section{HASIL DAN PEMBAHASAN}

Hasil

Penelitian ini dilaksanakan di SD Negeri 1 Pertima. Penelitian pengembangan ini menghasilkan prototype media ini, menghasilkan media pembelajaran interaktif berbasis Articulate Storyline 3 dengan games yang teruji validasinya, serta respon praktisi dan peserta didik terhadap pembelajaran interaktif berbasis Articulate Storyline 3 dengan games. Hasil pengembangan media ini diperoleh melalui beberapa tahapan yaitu tahap analisis, desain dan pengembangan. Tahap implementasi dan evaluasi tidak dilaksanakan karena situasi dan kondisi pandemi Covid-19. Tahap analisis dilakukan dengan analisis kurikulum, analisis kebutuhan, analisis peserta didik, dan analisis media. Tahap analisis dilakukan dengan studi dokumen, observasi dan mewawancarai guru kelas V SD Negeri 1 Pertima yaitu bahwa cakupan materi muatan IPA terutama subtema 3 pada buku tema maupun LKS peserta didk masih terbatas, sehingga diperlukan pegembangan materi agar sesuai dengan KD dan indikator yang diharapkan. Penggunaan media saat proses pembelajaran masih kurang khususnya media pembelajaran yang memanfaatkan teknologi. Hal ini dikarenakan kurangnya memanfaatkan prasarana dan sarana yang ada di sekolah. Dengan begitu, diperlukan pengembangan media pembelajaran interaktif berbasis Articulate Storyline 3 dengan games pada subtema 3 lingkungan dan manfaatnya kelas V SD. Tahap desain, dilakukan prototype (rancang bangun) dan pembuatan instrumen media pembelajaran interaktif berbasis Articulate Storyline 3 yang akan dikembangkan.

Adapun topik yang dipilih yaitu subtema 3 lingkungan dan manfaatnya. Pada rancangan media, dilakukan pembuatan desain background menggunakan aplikasi Microsoft Power Point, ditunjukkan pada gambar 1. Tahap pengembangan, dilakukan pembuatan media berdasarkan rancangan yang telah disetujui oleh dosen pembimbing. Media pembelajaran interaktif berbasis Articulate Storyline 3 dengan games yang dibuat terdiri dari 6 scene. 6 scene yaitu opening, pembuka, kompetensi, menu, referensi, dan biografi penyusun, ditunjukkan pada gambar 2. Setelah media pembelajaran interaktif berbasis Articulate Storyline 3 dengan games pada subtema 3 lingkungan dan manfaatnya kelas V SD dikembangkan, tahap selanjutnya yang dilkukan adalah uji coba untuk mengetahui validitas media dalam penelitian ini. Hasil validitas media pembelajaran interaktif berbasis Articulate Storyline 3 dengan games untuk ahli materi memperoleh indeks terendah pada ahli media sebesar 0,67 dan yang tertinggi sebesar 1, ahli media memperoleh indeks terendah pada ahli media sebesar 0,67 dan yang tertinggi sebesar 1 , ahli desain memperoleh indeks terendah pada ahli media sebesar 0,67 dan yang tertinggi sebesar 1, respon praktisi memperoleh skor rata-rata sebesar 3,92 dengan kualifikasi sangat baik. Respon peserta didik melalui perorangan memperoleh skor rata-rata sebesar 3,82 dengan kualifikasi sangat baik. Respon peserta didik melalui kelompok kecil memperoleh skor rata-rata sebesar 3,76 dengan kualifikasi sangat baik. Saat melaksanakan uji validitas media pembelajaran interaktif berbasis Articulate Storyline 3 dengan games didapatkan review dari para ahli. Hasil review dari ahli media, ahli materi, dan praktisi tersaji pada Tabel 6.
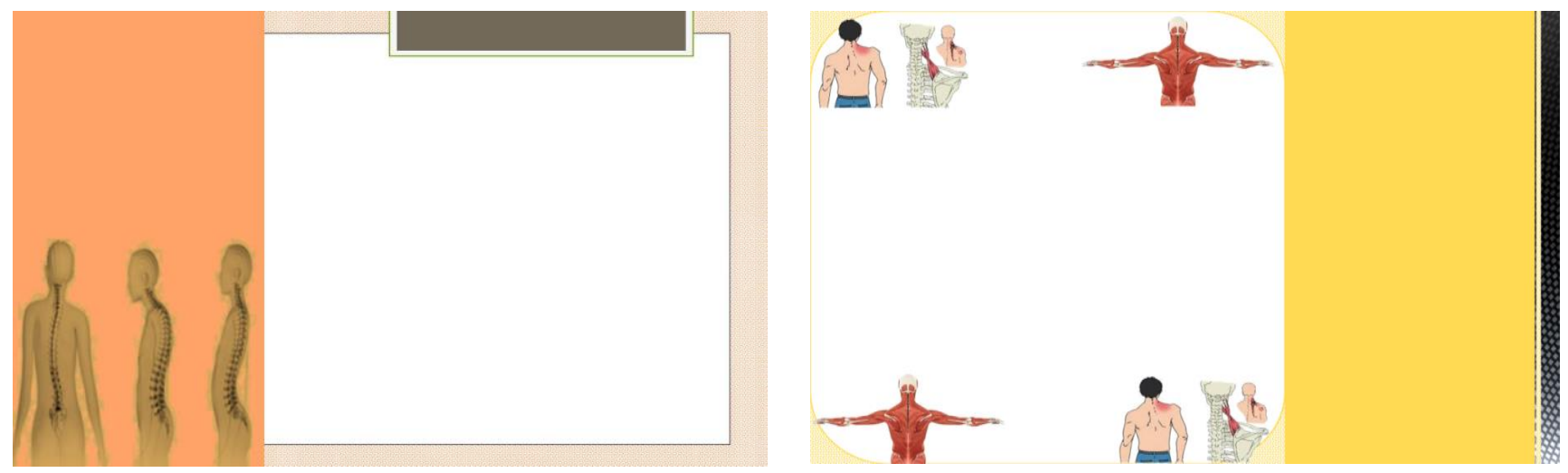

Gambar 1. Desain Background Media 

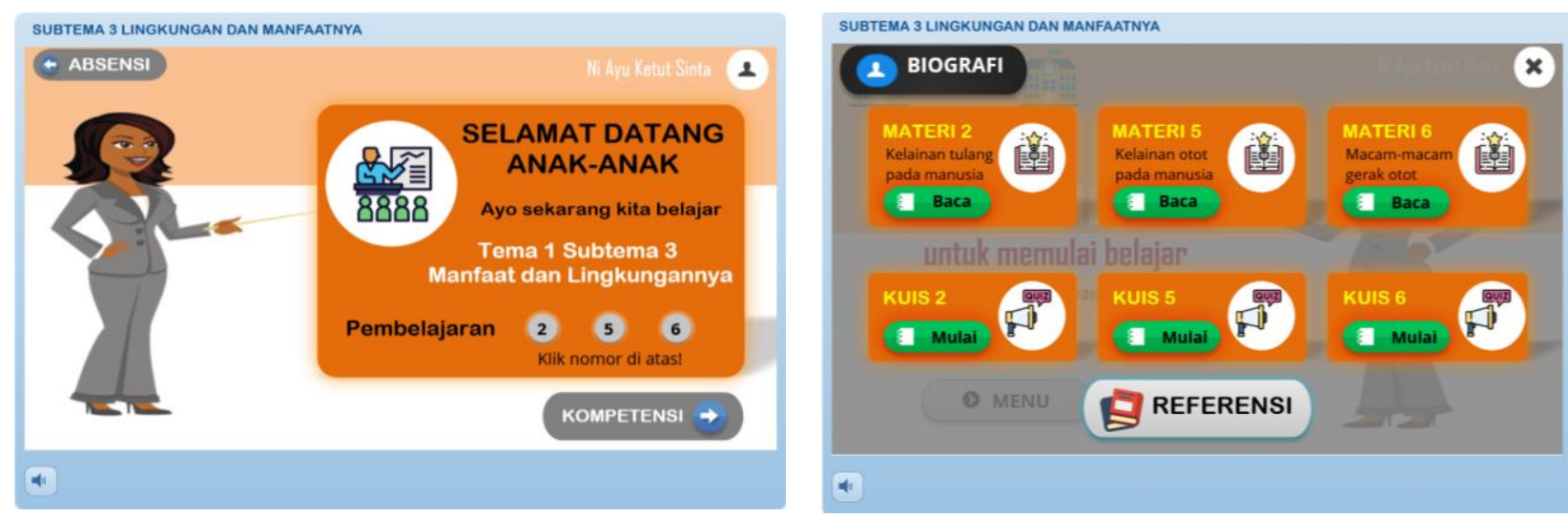

Gambar 2. Media Pembelajaran Interaktif Berbasis Articulate Storyline 3 dengan Games

Tabel 6. Masukan, Saran dan Komentar

\begin{tabular}{cl}
\hline No & \multicolumn{1}{c}{ Masukan, Saran dan Komentar } \\
\hline 1 & Pisahkan menu materi dengan menu utama \\
2 & Tambahkan tombol ke menu utama/home/halaman awal. \\
3 & Tambahkan pedoman/ petunjuk penggunaan media \\
4 & Jelaskan langkah-langkah pembelajaran,bisa dijadikan satu dengan petunjuk penggunaan media \\
5 & Hindari teks bawah ke atas seperti pada kompetensi inti \\
6 & Indikator diketik yang rapi \\
7 & Biografi diganti identitas pengembang \\
8 & Memberikan tanda pada konsep penting yang harus dikuasai peserta didik dengan menambah-kan \\
& warna atau tanda pada konsep \\
\hline
\end{tabular}

Penelitian pengembangan ini menghasilkan media penbelajaran interaktif berbasis Articulate Storyline 3 dengan games pada subtema 3 lingkungan dan manfaatnya kelas V SD. Dikembangkannya media penbelajaran interaktif berbasis Articulate Storyline 3 dengan games bertujuan untuk memfasilitasi peserta didik agar lebih mudah memahami materi yang dipelajari dalam proses pembelajaran. Selain itu, media ini membantu guru dalam menjelaskan materi. Berdasarkan teori perkembangan kognitif menurut piaget menyatakan bahwa anak sekolah dasar pada usia 6-12 tahun berada pada tahap operasional konkret. Pada tahap ini, anak sudah cukup matang untuk menggunakan pemikiran logika atau operasi, tetapi hanya untuk objek fisik belum dapat berpikir secara abstrak (Ibda, 2015), sehingga memerlukan bantuan berupa media pembelajaran pada proses pembelajaran untuk mengkonkritkan sesuatu yang abstrak. Pembuatan atau pemilihan media pembelajaran harus disesuaikan dengan karakteristik peserta didik yang beraneka ragam dan gaya belajar yang berbeda-beda seperti gaya belajar visual, auditorial, dan kinestetik (Fatmawati et al., 2020). Penerapan media pembelajaran interaktif berbasis Articulate Storyline 3 dengan games dapat membantu peserta didik yang memiliki gaya belajar yang berbeda-beda karena media ini merupakan media gabungan dari teks, gambar, video, musik dan animasi-animasi.

Hasil penelitian menunjukkan bahwa media pembejalaran interaktif berbasis Articulate Storyline 3 dengan games pada subtema 3 lingkungan dan manfaatnya kelas V SD dinyatakan valid. Hal ini karena penilaian aspek materi meliputi aspek kurikulum, aspek materi dan aspek tata bahasa. Aspek materi yang disajikan dalam media pembelajaran interaktif yang dikembangkan telah dipaparkan dengan jelas, menarik, serta sesuai dengan tujuan pembelajaran. Tujuan pembelajaran pada media pembelajaran interaktif sudah sesuai dengan kompetensi dasar dan indikator. Selain itu, bahasa yang digunakan dalam media pembelajaran interaktif sudah sesuai dengan karakteristik peserta didik. Dengan diterapkannya media pembelajaran interaktif berbasis model pembelajaran guided inquiry (inkuiri terbimbing) pada materi gaya terdapat peningkatan hasil belajar peserta didik, sehingga dapat dikatakan bahwa penggunaan media pembelajaran interaktif dapat meningkatkan pemahaman peserta didik dalam pembelajaran IPA pada subtema 3 lingkungan dan manfaatnya di kelas $\mathrm{V}$ (Annisa \& Simbolon, 2018). Sejalan dengan hal tersebut, penggunaan media pembelajaran interaktif dalam pembelajaran juga dapat memperbaiki proses dan meningkatkan hasil belajar peserta didik. Berdasarkan uji produk ahli materi, ahli media, dan uji coba lapangan meliputi uji perorangan, uji kelompok kecil, dan uji lapangan memeroleh hasil validitas valid, sehingga media pembelajaran interaktif berbasis komputer pada mata pelajaran IPA SD kelas V materi gaya, gerak dan energi dikatakan layak untuk digunakan (Salam et al., 2019). Selain itu penilaian aspek media meliputi aspek desain tampilan, aspek video, aspek animasi, dan aspek kemudahan penggunaan media. Kemudahan penggunaan media yang dikembangakn disajikan agar peserta didik terbantu saat menjalankan media pembelajaran interaktif ini. Keberagaman penyajian materi dengan video, teks, 
animasi-animasi dan gambar disajikan dengan baik sehingga menjadi lebih menarik dan dapat menumbuhkan motivasi belajar. Selain itu kualitas dan tampilan media video yang dikembangkan sudah sesuai dengan syaratsyarat media yang baik, yaitu efektif, efisien, dan komunikatif. Berdasarkan uji ahli media, ahli materi, dan ahli bahasa, multimedia interaktif Berbasis Articulate Storyline yang dikembangkan menunjukkan bahwa multimedia interaktif Berbasis Articulate Storyline yang dikembangkan layak dan efektif digunakan dalam menunjang proses pembelajaran dan dapat meningkatkan motivasi peserta didik (Aulia \& Masniladevi, 2021; Rafmana \& Chotimah, 2018).

Aspek-aspek yang dinilai pada aspek desain, sehingga tercapainya kualifikasi sangat baik yaitu, 1) aspek ketepatan, aspek kejelasan, aspek minat/perhatian, aspek kualitas kuis, dan aspek dapat memberikan dampak bagi peserta didik. Aplikasi media pembelajaran android menggunakan Articulate Storyline 3 yang dapat membantu memudahkan penyampaian materi dengan tambahan fitur kompetensi, kuis, video pembelajaran, dan glosarium yang dapat diakses secara offlline serta kemudahan pengunduhan pada web yang telah disediakan dilengkapi buku panduan penggunaannya. Media pembelajaran ini telah divalidasi oleh ahli materi dan ahli media yang hasilnya sangat layak untuk digunakan (Rohmah \& Bukhori, 2020; Salwani \& Ariani, 2021). Respon praktisi memperoleh kualifikasi sangat baik melalui aspek kurikulum, aspek materi, aspek tata bahasa, aspek desain tampilan, aspek video, aspek animasi, aspek kemudahan penggunaan media, aspek ketepatan, aspek kejelasan, aspek minat/perhatian, aspek kualitas kuis, dan aspek dapat memberikan dampak bagi peserta didik. Media pembelajaran Articulate storyline dapat digunakan sebagai media pembelajaran yang dapat membantu guru dalam menjelasakn materi pembelajaran dengan nilai respon praktisi sangat baik (Aulia \& Masniladevi, 2021; Rianto, 2020). Sehingga media pembelajaran Articulate Storyline layak digunakan dalam proses pembelajaran. Adapun aspek-aspek yang dinilai untuk respon peserta didik, sehingga tercapainya kualifikasi sangat baik yaitu aspek menarik minat peserta didik, aspek penyajian materi, aspek meningkatkan perhatian peserta didik, dan aspek memotivasi. Media pembelajaran interaktif berbasis articulate storyline memperoleh hasil rating yang dinyatakan sangat layak. Sedangkan angket respon siswa terhadap media pembelajaran interaktif berbasis articulate storyline memperoleh hasil rating yang dinyatakan sangat baik (Yumini \& Rakhmawati, 2015). Media pembelajaran interaktif berbasis Articulate Storyline layak digunakan sebagai media pembelajaran yang efektif dengan memperoleh respon siswa dengan kategori sangat baik(Andrizal \& Arif, 2017).

Melihat temuan penelitian ini secara keseluruhan, data-data hasil validitas penelitian materi, media, dan desain media pembelajaran interaktif berbasis Articulate Storyline 3 dengan games pada subtema 3 lingkungan dan manfaatnya kelas V SD, kemudian respon praktisi dan peserta didik diatas yang memperoleh hasil keseluruhan sangat baik. Maka dengan demikian, media pembelajaran interaktif berbasis Articulate Storyline 3 dengan games pada subtema 3 lingkungan dan manfaatnya kelas V SD dinyatakan valid dan layak untuk digunakan dalam proses pembelajaran. Penggunaan media pembelajaran interaktif berbasis Articulate Storyline 3 dengan games dapat meningkatkan motivasi dan hasil belajar khususnya muatan IPA apabila tahap implementasi dan tahap evaluasi dilaksanakan, disebabkan karena beberapa hal yaitu: 1) media pembelajaran interaktif berbasis Articulate Storyline 3 dengan games menyajikan materi yang mudah dipahami peserta didik, 2) media pembelajaran interaktif berbasis Articulate Storyline 3 dengan games menyajikan materi singkat, jelas, dan padat tanpa mengurangi makna pada materi tersebut, 3) media pembelajaran interaktif berbasis Articulate Storyline 3 dengan games menyajikan materi tidak hanya teks saja melainkan gambar dan juga video serta animasi-animasi yang diberikan akan menambah minat dan motivasi belajar peserta didik, dan 4) media pembelajaran interaktif berbasis Articulate Storyline 3 dengan games menyajikan materi, kuis-kuis dan games untuk melatih pemahaman materi yang telah dipelajarinya hasil kuis juga langsung dapat dilihat peserta didik.

\section{SIMPULAN}

Media pembelajaran interaktif berbasis Articulate Storyline 3 dengan games pada subtema 3 lingkungan dan manfaatnya kelas V SD termasuk pada kategori sangat baik dan dinyatakan valid. Hal ini didapatkan dari hasil validitas pada aspek materi, aspek media, aspek desain, respon praktisi dan respon peserta didik serta mendapatkan komentar-komentar untuk merevisi media tujuannya agar media menjadi lebih baik. Memanfaatkan media dalam pembelajaran ini dapat meningkatkan motivasi belajar peserta didik. Selain itu, rekomendasikan hasil penelitian yaitu media pembelajaran interaktif berbasis Articulate Storyline 3 dengan games pada subtema 3 lingkungan dan manfaatnya kelas V SD layak untuk dikembangkan sehingga memberikan kontribusi positif terhadap peningkatan hasil belajar IPA peserta didik.

\section{DAFTAR PUSTAKA}

Abdulrahaman, M. D., Faruk, N., Oloyede, A. A., Surajudeen-Bakinde, N. T., Olawoyin, L. A., Mejabi, O. V., ImamFulani, Y. O., Fahm, A. O., \& Azeez, A. L. (2020). Multimedia tools in the teaching and learning processes: A systematic review. Heliyon, 6(11), e05312. https://doi.org/10.1016/j.heliyon.2020.e05312.

Andreani, W., \& Ying, Y. (2019). "PowPow" interactive game in supporting English vocabulary learning for elementary students. Procedia Computer Science, 157, 473-478. 
https://doi.org/10.1016/j.procs.2019.09.005.

Andrizal, A., \& Arif, A. (2017). Pengembangan Media Pembelajaran Interaktif Pada Sistem E-Learning Universitas Negeri Padang. INVOTEK: Jurnal Inovasi Vokasional Dan Teknologi, 17(2), 1-10. https://doi.org/10.24036/invotek.v17i2.75.

Annisa, N., \& Simbolon, N. (2018). Pengembangan Media Pembelajaran Interaktif Ipa Berbasis Model Pembelajaran Guided Inquiry Pada Materi Gaya Di Kelas Iv Sd Negeri 101776 Sampali. School Education Journal Pgsd Fip Unimed, 8(2), 217-229. https://doi.org/10.24114/sejpgsd.v8i2.10199.

Asyhari, A., \& Silvia, H. (2016). Pengembangan Media Pembelajaran Berupa Buletin dalam Bentuk Buku Saku untuk Pembelajran IPA Terpadu. Jurnal Ilmiah Pendidikan Fisika Al-Biruni, 5(1), 1-13. https://doi.org/10.24042/jpifalbiruni.v5i1.100.

Candiasa, I. M. (2011). Penguji Instrumen Penelitian Disertasi Aplikasi ITEMAN dan BIGSTEPS (Undiksha P).

Courage, M. L. (2016). Interactive technologies: Tablets, smartphones, and learning. In The Curated Reference Collection in Neuroscience and Biobehavioral Psychology. Elsevier. https://doi.org/10.1016/B978-0-12809324-5.23561-X.

Dewi, W. A. F. (2020). Dampak COVID-19 terhadap Implementasi Pembelajaran Daring di Sekolah Dasar. Edukatif : Jurnal Ilmu Pendidikan, 2(1), 55-61. https://doi.org/10.31004/edukatif.v2i1.89.

Dong, C., Cao, S., \& Li, H. (2020). Young children's online learning during COVID-19 pandemic: Chinese parents' beliefs and attitudes. Children and Youth Services Review, 118(June), 105440. https://doi.org/10.1016/j.childyouth.2020.105440.

Fatmawati, F., Hidayat, M. Y., Damayanti, E., \& Rasyid, M. R. (2020). Gaya Belajar Peserta Didik Ditinjau Dari Perbedaan Jenis Kelamin. Al Asma: Journal of Islamic Education, 2(1), 23. https://doi.org/10.24252/asma.v2i1.13472.

Harjanta, A. T. J., \& Herlambang, B. A. (2018). Rancang Bangun Game Edukasi Pemilihan Gubernur Jateng Berbasis Android Dengan Model ADDIE. Jurnal Transformatika, 16(1), 91. https://doi.org/10.26623/transformatika.v16i1.894.

Huang, S. Y., Kuo, Y. H., \& Chen, H. C. (2020). Applying digital escape rooms infused with science teaching in elementary school: Learning performance, learning motivation, and problem-solving ability. Thinking Skills and Creativity, 37(129), 100681. https://doi.org/10.1016/j.tsc.2020.100681.

Ibda, F. (2015). Perkembangan Kognitif: Teori Jean Piaget. Intelektualita, 3(1), 242904. https://jurnal.arraniry.ac.id/index.php/intel/article/view/197.

Luh, N., Rasvani, A., Agung, I. G., \& Wulandari, A. (2021). Pengembangan Media Pembelajaran Aplikasi MaCa ( Materi Pecahan ) Berorientasi Teori Belajar Ausubel Muatan Matematika. 9(1), 74-81. http://dx.doi.org/10.23887/jjpgsd.v9i1.33586.

Mahesti, G., \& Koeswanti, H. D. (2021). Pengembangan Media Pembelajaran Permainan Monopoli Asean untuk Meningkatkan Hasil Belajar Tema 1 Selamatkan Makhluk Hidup Pada Siswa Kelas 6 Sekolah Dasar. Mimbar PGSD Undiksha, 9(1), 30-39. http://dx.doi.org/10.23887/jjpgsd.v9i1.33586.

Mishra, L., Gupta, T., \& Shree, A. (2020). Online teaching-learning in higher education during lockdown period of COVID-19 pandemic. International Journal of Educational Research Open, June, 100012. https://doi.org/10.1016/j.ijedro.2020.100012.

Putri, N. M. C. D., Ardana, I., \& Agustika, G. N. S. (2018). Pengaruh Model Discovery Learning Berbantuan Lingkungan Terhadap Kompetensi Pengetahuan IPA Siswa Kelas V. International Journal of Elementary Education, 2(3), 211. https://doi.org/10.23887/ijee.v2i3.15960.

Rafmana, H., \& Chotimah, U. (2018). Pengembangan Multimedia Interaktif Berbasis Articulate Storyline Untuk Meningkatkan Motivasi Belajar Siswa Pada Mata Pelajaran PKn Kelas XI Di SMA Srijaya Negara Palembang. Jurnal Bhinneka Tunggal $\quad$ Ika, https://ejournal.unsri.ac.id/index.php/jbti/article/view/7898.

Rianto, R. (2020). Pembelajaran Interaktif Berbasis Articulate Storyline 3. Indonesian Language Education and Literature, 6(1), 84. https://doi.org/10.24235/ileal.v6i1.7225.

Rohmah, F. N., \& Bukhori, I. (2020). Pengembangan Media Pembelajaran Interaktif Mata Pelajaran Korespondensi Berbasis Android Menggunakan Articulate Storyline 3. Economic \& Education Journal, 2, 169-182. https://doi.org/10.33503/ecoducation.v2i2.892.

Ruipérez-Valiente, J. A., \& Kim, Y. J. (2020). Effects of solo vs. collaborative play in a digital learning game on geometry: Results from a K12 experiment. Computers and Education, 159(September). https://doi.org/10.1016/j.compedu.2020.104008.

Salam, N., Safei, \& Jamilah. (2019). Pengembangan Media Pembelajaran Ular Tangga Pada Materi Sistem Saraf. AL-Ahya, 01(01), 219-232. http://repositori.uin-alauddin.ac.id/5613/.

Salwani, R., \& Ariani, Y. (2021). Pengembangan Media Pembelajaran Tema 3 Subtema 3 Berbasis Articulate Storyline 3 di Kelas Va SDIT Mutiara Kota Pariaman. 5, 409-415. Jurnal Pendidikan Tambusai. https://jptam.org/index.php/jptam/article/view/963.

Sari, R. K., \& Harjono, N. (2021). Pengembangan Media Pembelajaran Interaktif Berbasis Articulate Storyline 
pada Mata Pelajaran IPA Siswa Kelas VII. Jurnal Pedagogi dan Pembelajaran, 4(1), 122-130. //dx.doi.org/10.23887/jp2.v4i1.33356.

Setyaningsih, S., Rusijono, R., \& Wahyudi, A. (2020). Pengaruh Penggunaan Media Pembelajaran Interaktif Berbasis Articulate Storyline Terhadap Motivasi Belajar dan Hasil Belajar Siswa Pada Materi Kerajaan Hindu Budha di Indonesia. Didaktis: Jurnal Pendidikan Dan Ilmu Pengetahuan, 20(2), 144-156. https://doi.org/10.30651/didaktis.v20i2.4772.

Suartama, I. K. (2016). Evaluasi dan Kriteria Kualitas Multimedia Pembelajaran. Universitas Pendidikan Ganesha. Sudarma, I. K., \& dkk. (2015). Desain Pesan Kajian Analisis Desain Visual Teks dan Image. Graha Ilmu.

Sugiyono. (2015). Metode Penelitian. Metode Penelitian.

Sukendro, S., Habibi, A., Khaeruddin, K., Indrayana, B., Syahruddin, S., Makadada, F. A., \& Hakim, H. (2020). Using an extended Technology Acceptance Model to understand students' use of e-learning during Covid-19: Indonesian sport science education context. Heliyon, 6(11), e05410. https://doi.org/10.1016/j.heliyon.2020.e05410.

Syah, R. H. (2020). Dampak Covid-19 pada Pendidikan di Indonesia: Sekolah, Keterampilan, dan Proses Pembelajaran. SALAM: Jurnal Sosial Dan Budaya Syar-I, $7(5)$. https://doi.org/10.15408/sjsbs.v7i5.15314.

Tuma, F., Malgor, R. D., \& Nassar, A. K. (2021). Actions to enhance interactive learning in surgery. Annals of Medicine and Surgery, 64(March), 102256. https://doi.org/10.1016/j.amsu.2021.102256.

Wahyuningtyas, R., \& Sulasmono, B. S. (2020). Pentingnya Media dalam Pembelajaran Guna Meningkatkan Hasil Belajar di Sekolah Dasar. Edukatif: Jurnal Ilmu Pendidikan, 2(1), 23-27. https://doi.org/10.31004/edukatif.v2i1.77.

Wijayanto, R., \& Santoso, R. H. (2017). Pengembangan Bahan Ajar Matematika Dengan Pendekatan Problem Solving Berorientasi Pada Kemampuan Pemecahan Masalah. Journal of Education, 1(1), 4. https://jbasic.org/index.php/basicedu/article/view/628.

Wiwik Saptiani, N. W., \& Astawan, I. G. (2020). Pengaruh Model Pembelajaran TPS Berbasis Lingkungan Terhadap Sikap Peduli Lingkungan Dan Kompetensi IPA. International Journal of Elementary Education, 4(1), 44. https://doi.org/10.23887/ijee.v4i1.24332.

Yumini, S., \& Rakhmawati, L. (2015). Pengembangan Media Pembelajaran Interaktif Berbasis Articulate Storyline Pada Mata Diklat Teknik Elektronika Dasar Di Smk Negeri 1 Jetis Mojokerto. Jurnal Pendidikan Teknik Elektro, 4(3), 845-849. https://ejournal.unesa.ac.id/index.php/jurnal-pendidikan-teknikelektro/article/view/12673. 